\title{
Brain transplantation, personal identity and medical ethics
}

\author{
Raanan Gillon Imperial College of Science, Technology and Medicine, University of London
}

Why, readers might ask themselves, does this issue of the journal contain a paper on brain tissue transplantation and personal identity 1 - what is the connection between this and medical ethics, the journal's subject matter? Certainly the paper does not address the usual medical ethics issues associated with transplantation, such as benefits and harms to recipients, donors and society; respect for autonomy of recipients and donors or their proper proxies; use of different sorts of donors including fetuses, animals and living people; just distribution of resources whether in therapy or research; respect for people's rights; issues of legal justice, or ethical problems associated with the concept and criteria of brain death.

Instead the paper by Dr Northoff examines in considerable detail arguments deployed for and against the claim that brain tissue transplants, currently used in experimental treatments for Parkinson's disease, alter the personal identity of the recipients.

At its most dramatic and troublesome the relevance of this issue of personal identity is a major one for medical ethics, for brain transplantation might radically alter the recipient's personality, perhaps even impose on the recipient an entirely new personality, notably the personality of the donor. Indeed, if we consider the so far science fiction scenario of whole brain transplantation, referred to by Dr Northoff as a contrast to brain tissue transplantation, imposition of a new personality seems precisely what would happen, if we insist on thinking of such an operation as brain transplantation rather than, as seems conceptually more accurate, whole body transplantation from a brain dead donor to an isolated brain recipient. For it seems difficult to refute the claim that if it ever became possible successfully to transplant a complete and functioning brain from one human being into another, the procedure would involve donating to a person still present in a living brain a new body from a brain dead donor whose own dead brain had been removed. Thus if Susan's living complete brain was successfully transplanted into the skull of George's body (minus George's brain-dead brain) it would be Susan who survived, though in an uncomfortable new guise - for in her mirror and to everyone else she would appear to be George.
This sort of imaginary scenario would clearly have important medico-moral implications if it were ever to become technically possible to carry out such transplants. The confusion and distress of family and friends of the dead person whose body would live on as the body of another person - the person whose brain would now be in that body - would doubtless be enormous. Significant too (even assuming that a body of the same sex could have been found) would be the confusion and distress of the person-of-theliving-brain, now disguised in a new body. Yet if the alternative for that person-of-the-living-brain had been inevitable death - or even, perhaps, continuing life as a quadriplegic patient, totally dependent on others - some such people would be likely to prefer to live integrated into what was previously another's body, rather than to die, or remain totally dependent on others, in their own.

The fundamental problem that would arise from such whole body transplantation is the confusion and distress about personal identity that it would create. For while our sense of personal identity is essentially one of our own experience - our continuity of consciousness, stretching back into our past in memory, taking in our current experiences and projected through our imagination into our future nonetheless we also identify with our body, within which and through which we have those experiences and express our personalities; and, crucially, it is through the appearance and actions of other people's bodies that we identify those other people.

Thus over and above the standard ethical problems associated with organ transplantation, brain transplantation can also bring with it potentially major additional medico-moral problems associated with issues of personal identity.

We cannot here enter the long and complex philosophical debate about which changes produce a change in identity and which changes are simply changes in the same persisting entity, important as these issues are in relation especially to personal identity and morality. Suffice it to note that not all changes, whether to our bodies or to our minds, either negate our continuing identity with ourselves or are morally undesirable. Indeed apart from the constant 
changes we all undergo, almost all medical interventions change us in body and/or mind. But they don't necessarily or indeed usually change our identities.

Even the major change of whole brain transplantation - or of whole body transplantation - can be seen, as above, not to entail a fundamental change in identity so much as an apparent change in identity; and the major additional ethical problems it would create relate not strictly to a change in personal identity (which remains that of the person-of-theliving-brain) so much as to the confusion and distress caused to all by this apparent change in personal identity.

One way of ameliorating such confusion and distress would be to ensure that if any such transplants were ever to be developed the face of the person whose living brain was to survive should survive with it - for so much of the external physical aspects of personal identity, a person's appearance, are associated with that person's face - indeed the very word "person" derives from the Latin word for the mask that actors used on the stage to represent a different person, notably the character they were impersonating.

A useful thought experiment concerning personal identity and brain transplantation was offered by that great physician-philosopher John Locke. He envisaged a transposition not of the brain but of the soul of a prince into a cobbler's body, the cobbler's soul having "deserted" his body. "Everyone sees", wrote Locke, that "he would be the same person with the prince, accountable only for the prince's actions [even though] ... he would be the same cobbler to everyone besides himself". ${ }^{2}$ These days many of us are clear that our consciousness - our self or soul as Locke put it - resides in our brain and is related to brain activity, (though of course people would explain this interrelationship in varying ways). Successful transplantation of a whole and functioning brain into another body can be seen as equivalent to Locke's transposition of the prince's soul into the cobbler's body. While others may think that it is still the same cobbler, and while the residual living body other than the brain is that of the same cobbler, so far as persons are concerned, it is the prince who now is integrated into the cobbler's body, and so far as persons are concerned what appears to be the cobbler is in fact the prince. As Locke points out, if the cobbler had committed a crime we would not, or should not, once we understood what had happened, blame the prince, now integrated into the cobbler's body; conversely if the prince had committed a crime we should not excuse him simply because he was now integrated into the cobbler's body.

But suppose we change the example; suppose to the cobbler's self-aware and functioning but severely impaired brain, we integrate by successful brain surgery a still functioning and also self aware part of the prince's brain. What ethical problems might be anticipated? One disturbing possibility would be that two "selves" would be aware of being trapped in one body. Thus the cobbler might feel partly controlled $\stackrel{\text { T. }}{\frac{0}{8}}$. by, perhaps invaded by, another person, the prince, while the prince might feel imprisoned not only in $\vec{F}$ the body of the cobbler, but also partly controlled by, perhaps invaded by, the cobbler's personality. Of등 course, the two might learn to get on very well $\frac{\bar{s}}{\text {. }}$ together, perhaps even to feel augmented by each $\widehat{\widetilde{\phi}}$ other, perhaps even to become integrated into one $\stackrel{0}{0}$ person, a single blend of what used to be two minds. For all these alternatives major ethical problems $\overrightarrow{0}$ arise, not only as a result of confusion and distress $\overrightarrow{-}$ about personal identity, but also from restrictions ${ }_{\sigma}^{\omega}$ upon and changes to the identity of hitherto autonomous selves. It seems likely that the ethical disadvantages of any brain transplantation opera- $N$ tions that risked incorporating two self-aware con- $\omega$ sciousnesses, selves, or personalities, into one $\vec{\omega}$ head/body would be widely perceived greatly to $\vec{O}$ outweigh any potential benefits.

Suppose on the other hand that the partial brain $\vec{c}$ transplantation involved no adverse change in the recipient's self-awareness, no addition of, or sense of $\widetilde{\phi}$ being invaded or controlled by, some other person or $\vec{\theta}$ consciousness, but did offer a prospect of change for the better in a hitherto impaired brain function. Such seems to be the case in contemporary brain tissue transplantation for Parkinson's disease. From the recipient's point of view there is the potential benefit of improvement of previously intractable $\frac{\circ}{\Phi}$ Parkinsonian symptoms without any of the disadvantages described above that might stem from $\frac{0}{3}$ confusion about or changes in the patient's psychological experience of personal identity. Clearly such operations produce physical changes to the recipient's brain and incorporate parts of another $\overline{\bar{\delta}}$ human being's brain. However, there seems no reason to regard these as changing the identity of the 3 . recipient, any more than a kidney transplant or a prosthesis changes a recipient's identity.

Even if this issue of maintaining physical identity is ultimately a matter of stipulation rather than discovery or analysis, what seems undoubtedly true is that such brain changes would not necessarily be morally objectionable even if they did involve? changes in the patient's physical identity. The $O$ standard ethical problems of transplantation remain, $\mathbb{C}^{-}$ of course, in relation to such operations; and given 0 that fetuses are used as sources of brain tissue these problems are acute for those who morally abhor $\frac{0}{\mathbb{C}}$ abortion. But in such cases of partial brain trans- $\stackrel{+}{+}$ plantation the ethical problems do not, it seems 0 clear, stem from worries about identity.

\section{References}

1 Northoff G. Do brain tissue transplants alter personal $\overline{-}$ identity? Inadequacies of some "standard" arguments. 8 fournal of Medical Ethics 1996; 22: 174-80.

2 Locke J. An essay concerning human understanding. London: Dent (Everyman's Library), 1972. (First $\frac{0}{\overrightarrow{7}}$ published 1690). Book II, chapter XXVII. 